University of Wollongong

Research Online

Faculty of Engineering - Papers (Archive)

Faculty of Engineering and Information

Sciences

$1-1-2012$

\title{
Pesticide removal by a mixed culture of bacteria and white-rot fungi
}

\author{
Faisal I. Hai \\ University of Wollongong, faisal@uow.edu.au \\ Oska Modin \\ University of Tokyo \\ Kazuo Yamamoto \\ University Of Tokyo \\ Kensuke Fukushi \\ University Of Tokyo \\ Fumiyuki Nakajiam \\ University Of Tokyo
}

See next page for additional authors

Follow this and additional works at: https://ro.uow.edu.au/engpapers

Part of the Engineering Commons

https://ro.uow.edu.au/engpapers/4417

\section{Recommended Citation}

Hai, Faisal I.; Modin, Oska; Yamamoto, Kazuo; Fukushi, Kensuke; Nakajiam, Fumiyuki; and Nghiem, Long: Pesticide removal by a mixed culture of bacteria and white-rot fungi 2012, 459-462.

https://ro.uow.edu.au/engpapers/4417

Research Online is the open access institutional repository for the University of Wollongong. For further information contact the UOW Library: research-pubs@uow.edu.au 


\section{Authors}

Faisal I. Hai, Oska Modin, Kazuo Yamamoto, Kensuke Fukushi, Fumiyuki Nakajiam, and Long Nghiem 


\title{
Pesticide Removal by a Mixed Culture of Bacteria and White Rot Fungi
}

\author{
Faisal Ibney Hai ${ }^{1,4,{ }^{*}, \alpha, \zeta}$, Oskar Modin ${ }^{2, \beta, \zeta}$, Kazuo Yamamoto ${ }^{1}$, Kensuke Fukushi ${ }^{3}$, Fumiyuki \\ Nakajima $^{1}$ and Long Duc Nghiem ${ }^{4}$ \\ ${ }^{1}$ Environmental Science Center, The University of Tokyo, \\ 7-3-1 Hongo, Bunkyo-ku, Tokyo, 113-0033, Japan. \\ ${ }^{2}$ Department of Urban Engineering, The University of Tokyo, \\ 7-3-1 Hongo, Bunkyo-ku, Tokyo, 113-8656, Japan.
}

\footnotetext{
${ }^{3}$ Integrated Research System for Sustainability Science, The University of Tokyo, 7-3-1 Hongo, Bunkyo-ku, Tokyo, 113-8654, Japan.
}

${ }^{4}$ Strategic Water Infrastructure Laboratory, School of Civil, Mining and Environmental Engineering, University of Wollongong, NSW 2522, Australia

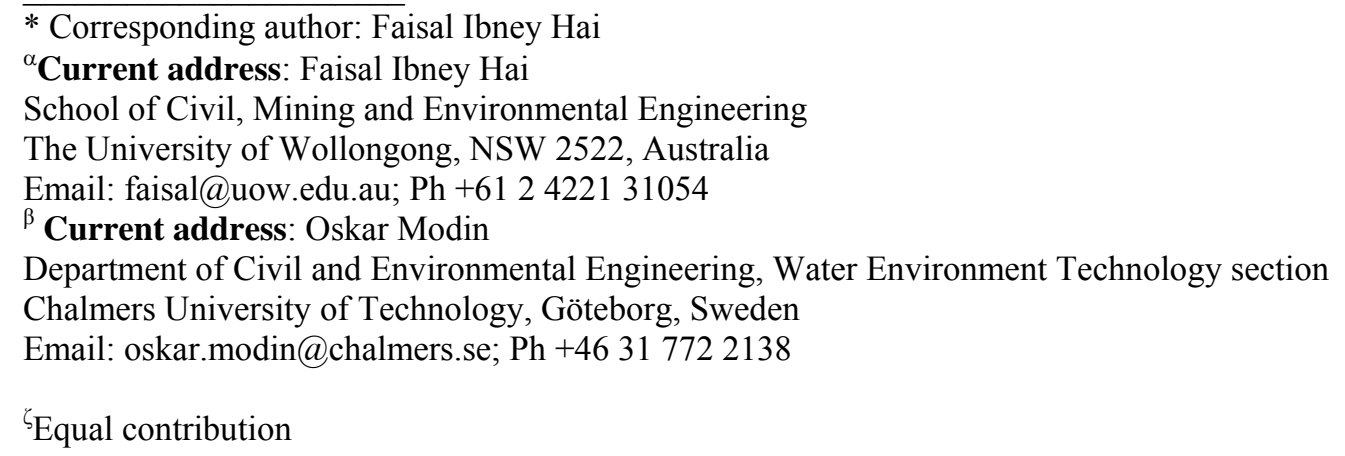

\section{Abstract}

Combining activated sludge cultures with microbes harboring specific degradation pathways could constitute a relevant process for the removal of toxic and recalcitrant organic substances from wastewater. Enhanced removal of three widely used recalcitrant pesticides from their liquid mixture was demonstrated by implementing a non-acclimated mixed culture of bacteria and white rot fungus. During an incubation period of 14 days, the mixed fungusbacteria culture achieved 47,98 , and $62 \%$ removal of aldicarb, atrazine and alachlor from the liquid phase, respectively. This compared favorably to batches containing only nonacclimated fungus or previously published removal rates with non-acclimated bacterial cultures. Biosorption along with biodegradation was responsible for the removal of the pesticides from the liquid phase. Potential application modes of the studied biodegradation process were also discussed.

Keywords: bioaugmentation, biodegradation, biosorption, pesticide, white rot fungi 


\section{Introduction}

The use of pesticides is ubiquitous in modern agriculture and is important to increase crop yield and reduce post-harvest losses. However, indiscriminate and excessive use of agricultural pesticides can lead to contamination of land and water. Emissions of pesticides come from both diffuse and point sources. The latter include mixing and loading facilities on the farm where spillages and leakages from the filling operation and spray equipment, and water from rinsing and cleaning of the equipment may contribute to pesticide contamination [1]. Wastewater generated in vegetable washing facilities and pesticide manufacturing plants are also important point sources of pollution.

Many pesticides are recalcitrant compounds and persist for long periods of time in the environment. Pesticides have been detected in ground- and surface waters used for potable water supply and have been linked to adverse human health effects [2]. The adverse effects of agricultural pesticide contamination extend to birds, wild animals and plants in the aquatic habitat. Because of the widespread use of pesticides in modern agricultural practice and their potential threat to the environment, the formulation of treatment methods for the removal of these pesticides from contaminated water is essential.

Biological treatment technologies are usually inexpensive and effective for a range of organic contaminants. However, owing to the recalcitrant structures of the pesticides, only specific bacterial and fungal species have been reported to be capable of degrading them [3]. Interestingly, in the soil environment, bacteria and fungi seem to adopt different but complementary metabolic pathways for the degradation of these recalcitrant pesticides [4]. For instance, the contributions of both bacteria and fungi to the degradation of a chloroaromatic fungicide - chlorothalonil - in soil were confirmed by a selective inhibition method [5].

To date, the number of studies investigating novel treatment techniques for the removal of pesticides from contaminated agricultural wastewater remains limited. The bacteria-dominated conventional activated sludge process has been proved to be ineffective for pesticide removal. 
While the importance of a mixed microbial community to initiate and complete pesticide removal in the soil environment has been convincingly demonstrated by several researchers, studies concerning the removal of pesticides from water/wastewater have been predominantly focused on selected bacterial or fungal species separately [6]. For instance, white rot fungi have been demonstrated to possess excellent capacity to initiate degradation of a wide variety of pesticides by means of their nonspecific extracellular enzyme systems. A few studies have explored the bioaugmentation synergy of enriched bacterial cultures with the conventional activated sludge [78]. However, there appears to be no report on the combination of fungi and bacteria to remove pesticide from the aqueous phase.

With the aim to address the important knowledge gap illustrated above, in this study the removal of three pesticides from their mixture using a mixed culture of bacteria and white rot fungi was investigated. The removal efficiency of the dissolved parent compounds were compared to a culture with only white-rot fungi and to previously published values with bacterial cultures. The importance, limitations, and potential application modes of the studied biodegradation process were also discussed.

\section{Materials and methods}

\subsection{Selected pesticides}

Three pesticides, namely, aldicarb, atrazine, and alachlor were selected in view of their widespread use and reported linkage to water pollution. Aldicarb is an N-methyl carbamate; it is an insecticide/ nematicide used on a wide range of crops including cotton, potatoes, sugarcane, and is applied as granules to the soil [3]. Atrazine is a triazine and is used as a herbicide on, for example, forests, grass, corn, and sorghum. Alachlor is a chloroacetanilide and also used as a herbicide on, for example, corn and beans. Stock solutions $\left(500 \mathrm{mg} \mathrm{L}^{-1}\right)$ of each of the three pesticides were prepared in pure methanol.

\subsection{Preparation of bioaugmented culture and nutrient medium}


Resource Center (NBRC), Japan was used for this study. Full-grown and enzyme secreting large flocs of fungi [9] were disintegrated into fine grains by sonication (Branson sonifier 450, CT, USA) for 5 minutes under sterile condition. The resulting biomass was then incubated for a week into 500 $\mathrm{mL}$ beakers each containing $100 \mathrm{~mL}$ growth medium at the optimum growth temperature of $28{ }^{\circ} \mathrm{C}$ on a shaker (BR-300LF, Taitec rotary bio-shaker, Japan) at $80 \mathrm{rpm}$. At the end of the incubation period approximately $0.5 \mathrm{~cm}$ granules exhibiting an enzymatic activity of approximately $30 \mu \mathrm{M}$ substrate $\min ^{-1} \mathrm{~g}^{-1}$ were obtained. On the other hand, activated sludge sample collected from Shibaura wastewater treatment plant, Tokyo, Japan was utilized for obtaining the mixed culture. The sludge was centrifuged under $2150 \times \mathrm{g}$ and reconstructed with Milli-Q water. The bioaugmented culture was obtained by adding equal amounts $(0.05 \mathrm{~g}$, dry wt.) of pure fungus granules and reconstituted activated sludge. Neither the mixed bacterial culture nor the fungus was acclimatized before incubation with pesticide.

A nutrient-sufficient growth medium previously optimized by Kapdan et al. [10] for $C$. versicolor was modified by adding a lesser amount of glucose $\left(1 \mathrm{~g} \mathrm{~L}^{-1}\right)$ and using ammonium nitrate $\left(0.13 \mathrm{~g} \mathrm{~L}^{-1}\right)$ as the nitrogen source instead of urea. The initial $\mathrm{pH}$ of the media was 4.5 .

\subsection{Batch test description}

The test solution was prepared by adding specified amounts from each of the pesticide stock solutions to autoclaved $\left(121{ }^{\circ} \mathrm{C}, 0.2 \mathrm{MPa}, 15 \mathrm{~min}\right)$ empty beakers $(8.5 \mathrm{~cm}$ diameter, $500 \mathrm{~mL}$ capacity), allowing the methanol to evaporate, and then adding $100 \mathrm{~mL}$ of the autoclaved nutrient medium.. The final concentration of each of the pesticides in the mixture was $10 \mathrm{mg} \mathrm{L}^{-1}$. The bioaugmented culture $(0.1 \mathrm{~g}$ (dry weight); reconstructed activated sludge: fungus $=1: 1)$ was aseptically transferred to the test solution. The beakers were loosely covered with aluminium foil and then placed under $28{ }^{\circ} \mathrm{C}$ on a shaker at $80 \mathrm{rpm}$. Beakers containing only fungus $(0.1 \mathrm{~g})$ and only activated sludge $(0.1 \mathrm{~g})$ were also incubated in order to assess the atrazine removal performance by single cultures. Same amount of autoclaved fungus and bacteria were incubated 
separately to assess the extent of atrazine removal owing to biosorption only. Atrazine was added into the nutrient media at a concentration of $1200 \pm 200 \mu \mathrm{g} \mathrm{L}^{-1}$ during the experiments with single cultures. The batch tests were carried out in duplicate and each batch test lasted 14 days.

\subsection{Analytical methods}

The pesticide concentrations were measured using HPLC coupled to a diode array detector (Hewlett Packard, 1100 series). The compounds were separated on a Novapak C18, $60 \AA$, $4 \mu \mathrm{m}, 3.9$ x $150 \mathrm{~mm}$ column with an acetonitrile / water eluent at the wavelength of $220 \mathrm{~nm}$ (atrazine) and $205 \mathrm{~nm}$, respectively. Pesticide concentrations above $0.05 \mathrm{mg} \mathrm{L}^{-1}$ could be quantified. Total organic carbon (TOC) and total nitrogen (TN) concentrations were measured with a TOC-TN analyzer (TOC-V, Shimadzu, Japan). The activity of fungal enzyme (Laccase) was measured by monitoring the change in absorbance at $468 \mathrm{~nm}$ due to the oxidation of the substrate (2,6-dimethoxyphenol) by enzyme at room temperature over a 2 min period as described in a previous study [9].

\section{Results and discussion}

\subsection{Pesticide removal}

Figure 1a depicts the reduction of aqueous phase concentration of each pesticide from the mixture containing the unacclimated fungus-bacteria and fungus-only cultures. Within 7 days, the concentrations of aldicarb, atrazine, and alachlor dropped by 82,77 , and $67 \%$, respectively, in the mixed cultures, and by 79,81 , and $59 \%$ in the fungus-only cultures. In comparison, in a previous study, we reported the removal efficiencies of these pesticides by an unacclimated bacterial culture under similar experimental conditions to be only $17, \sim 0$, and $35 \%$ for aldicarb, atrazine, and alachlor, respectively (Modin et al., 2008).

\section{[Figure 1]}

The concentration of all three pesticides in the fungus-only batches increased after day 7 of the incubation period. Results reported in Figure 1a suggests that the pesticides adsorbed temporarily onto the fungus biomass and later got released back to the aqueous phase. It is noteworthy that the selected pesticides are moderately hydrophobic. Hydrophobic interaction along with other Hai et al. (2012) Journal of the Taiwan Institute of Chemical Engineers, (43), 459-462 
mechanism such as ion exchange, surface complexation and hydrogen bonding can play a significant role in sorption of these compounds to solid substrate. Therefore, in good agreement with several previous studies [11], biosorption of the selected pesticides to the fungus biomass is not entirely unexpected. However, the observed increase in liquid phase concentration at the later stage may be attributed to desorption of the non-biodegraded portion of the initially biosorbed pesticides.

A different trend was observed in the fungus-bacteria mixtures. The aldicarb concentration increased slightly suggesting release by the biomass after day 7. Atrazine, on the other hand, was almost completely removed from the aqueous phase. The alachlor concentration remained steady between day 7 and day 14 . The high removal of atrazine by the fungus-bacteria mixture is especially interesting since among the three tested pesticides, atrazine is generally considered the most persistent with a half-life typically over 100 days [12]. In contrast, in this study the removal of atrazine by the bioaugmented culture reached over $98 \%$ in two weeks. In additional experiments, where the extent of biosorption and biodegradation was assessed separately, it was confirmed that biodegradation of atrazine did not occur in fungus-only and activated sludge-only cultures (Figure 1b).

The success of the fungus-bacterial mixture for removal of atrazine and alachlor can be explained in analogy to a relevant observation made in the soil environment by Levanon [13]. It was reported that the mineralization of alkyl-side chains of alachlor and alkyl-amino-side chains of atrazine was mainly due to fungal activity. However, neither heterocyclic ring-labelled atrazine nor aromatic ring-labelled alachlor were degraded when fungi or bacteria were separately inhibited. The importance of combining fungi and bacteria can be further recognized by comparing the removal rates observed in this study with that by individual bacterial and fungal species or enriched mixed bacterial cultures reported in the literature. For instance, the fungus $C$. versicolor was reported to take 42 days to reach the maximum $86 \%$ degradation of atrazine in liquid culture [14]. Knapp et al. [15] reported a half life ranging 16-122 days of alachlor in surface water environment. 
While the culture conditions can be significantly different in individual studies, thereby restricting direct comparison of removal efficiencies, it can generally be stated that the mixed fungus-bacteria culture implemented in this study exhibited high pesticide removal capacity, despite not being acclimated to the pesticides. In practice, the possibility to use non-acclimated microbial cultures for pesticide degradation may be beneficial since the use of pesticides, and thus the pesticide load in wastewater, vary significantly during a year.

\subsection{Fungi morphology and extent of biosorption}

For the fungus-bacteria mixture, the initial distinct fungus granules appeared disintegrated at the end of the incubation period. Disintegration, but to a lesser extent, was also observed when the fungus was incubated alone (Figure 2). These results show that the presence of bacteria had a clear effect on the morphology of the fungus.

\section{[Figure 2]}

The mechanisms of pesticide removal from the liquid phase in this study are not entirely clear. Physical adsorption or uptake by the biomass without biochemical degradation of the pesticides appears to be a major removal mechanism by the fungus-only cultures. The pesticides were initially taken up by the fungus but later released, perhaps as a result of the change in morphology (Figure 2) and also the depletion of nutrients in the growth medium as demonstrated by the TOC and TN concentration over the incubation period (Figure 3).

\section{[Figure 3]}

For the fungus-bacteria mixed cultures, biochemical degradation and physical adsorption/uptake both appears to have played roles for removing pesticides from the liquid phase. In the case of aldicarb, there is a slight increase in concentration between day 7 and day 12 . However, for atrazine there is a clear decrease to nearly non-detectable levels, and for alachlor the concentration remains stable between day 7 and day 14 (Figure 1a). This suggests that it was not biosorption alone that was responsible for the pesticide removal, but biochemical degradation also played a role, at least for atrazine. No biodegradation or biosorption of atrazine was noticed in 
bacteria-only culture. On the other hand, temporary adsorption of atrazine onto fungus was observed, but again no biodegradation was detected in fungus-only culture (Figure 1b). Therefore synergistic biodegradation of atrazine by the fungus-bacteria mixed culture following its initial biosorption appears to be very likely. Thus despite comparatively more pronounced disintegration of the biomass as well as the reduction of residual nutrient levels in test solution (Figures 2 and 3) the bioaugmented culture demonstrated better removal.

As described in section 3.1, the pesticide removal rate by the fungi-bacteria culture was high compared to the previously published values by our group [12] for bacterial cultures under similar conditions. The results from the current study suggest that the presence of bacteria has a clear effect on the fungus morphology (Figure 2) and nutrient depletion from the test solution (Figure 3). Further research is necessary to establish how bacteria affect fungus morphology and fungal activity (enzyme secretion). For further insight into the reported results, the kinetics of pesticide removal and its toxic effect on bioaugmented culture need to be studied under a range of pesticide dosage and varying ratios of fungus and activated sludge masses. Nevertheless, the results presented in the current study do suggest that combining fungus and bacteria for removing recalcitrant compounds such as pesticides from wastewater is beneficial.

\section{Conclusions}

This study showed that mixed cultures of bacteria and fungus can remove the pesticides aldicarb, atrazine, and alachlor from their mixture. Particularly atrazine was very effectively removed. The reported data demonstrated the complementary effect of combining bacteria and a fungal culture for improving the removal rates of the three selected recalcitrant pesticides. The results have important implications towards the development of a scaled-up treatment system for pesticide contaminated water.

\section{Acknowledgements}

A part of this study was carried out during the Japan Society for promotion of Science fellowship tenure of Dr. Faisal I. Hai at the University of Tokyo, Japan. Oskar Modin was 
of the analyses.

\section{References}

[1] Carter A. How pesticides get into water - and proposed reduction measures. Pestic Outlook 2000; 11(4):149-56.

[2] Gilliom RJ. Pesticides in the hydrologic system - what do we know and what's next? Hydrol Process 2001; 15(16):3197-201.

[3] Navaratna D, Shu L, Jegatheesan V. Existence, impacts, transport and treatments of herbicides in great barrier reef catchments in Australia. In: Virkutyte JV, Rajender S.; Jegatheesan, Veeriah, editor. Treatment of micropollutants in water and wastewater. London, UK: IWA publishing; 2010. p. 425-57.

[4] Ronhede S, Jensen B, Rosendahl S, Kragelund BB, Juhler RK, Aamand J. Hydroxylation of the Herbicide Isoproturon by Fungi Isolated from Agricultural Soil. Appl Environ Microbiol 2005; 71(12):7927-32.

[5] Mori T, Fujie K, Katayama A. Bacterial and fungal contributions to chlorothalonil degradation in soil. Soil Sci Plant Nutr 1998; 44(3):297-304.

[6] Osman KA, Ibrahim GH, Askar Al, Aba Alkhail ARA. Biodegradation kinetics of dicofol by selected microorganisms. Pestic Biochem Physiol 2008; 91(3):180-5.

[7] Kontchou CY, Gschwind N. Biodegradation of s-triazine compounds by a stable mixed bacterial community. Ecotoxicol Environ Saf 1999; 43(1):47-56.

[8] Liu C, Huang $\mathrm{X}$, Wang $\mathrm{H}$. Start-up of a membrane bioreactor bioaugmented with genetically engineered microorganism for enhanced treatment of atrazine containing wastewater. Desalination. 2008; 231(13):12-9.

[9] Hai FI, Yamamoto K, Nakajima F, Fukushi K. Factors governing performance of continuous fungal reactor during non-sterile operation - The case of a membrane bioreactor treating textile wastewater. Chemosphere. 2009; 74(6):810-7.

[10] Kapdan IK, Kargi F. Simultaneous biodegradation and adsorption of textile dyestuff in an activated sludge unit. Process Biochem 2002; 37:973-81.

[11] Bouju H, Buttiglieri G, Malpei F. Perspectives of persistent organic pollutants (POPS) removal in an MBR pilot plant. Desalination. 2008; 224(1-3):1-6.

[12] Modin O, Fukushi K, Yamamoto K. Simultaneous removal of nitrate and pesticides from groundwater using a methane-fed membrane biofilm reactor. Water Sci Technol 2008; 58(6):1273-9.

[13] Levanon D. Roles of fungi and bacteria in the mineralization of the pesticides atrazine, alachlor, malathion and carbofuran in soil. Soil Bio Biochem 1993; 25(8):1097-105.

[14] Bending GD, Friloux M, Walker A. Degradation of contrasting pesticides by white rot fungi and its relationship with ligninolytic potential. FEMS Microbiol Lett 2002; 212(1):59-63.

[15] Knapp CW, Graham DW, Berardesco G, deNoyelles F, Cutak BJ, Larive CK. Nutrient level, microbial activity, and alachlor transformation in aerobic aquatic systems. Water Res 2003; 37(19):4761-9. 
(a)
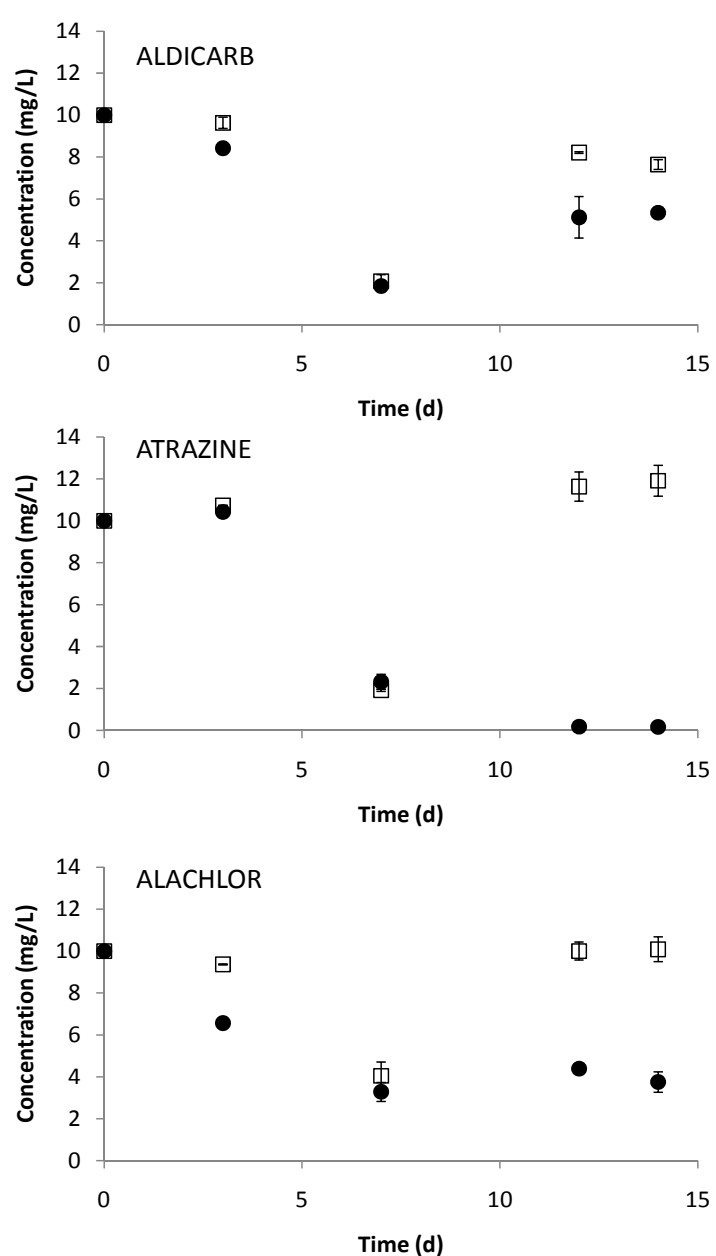

(b)

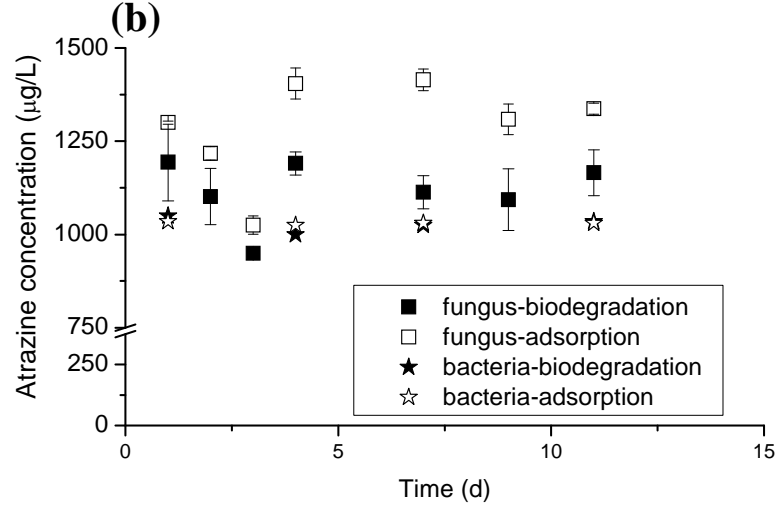

Figure 1. Change in liquid phase concentration of the pesticide(s) over the incubation period. Error bars indicate the deviations between two replicates. (a) The batch test solution comprised of three pesticides (each at $10 \mathrm{mg} \mathrm{L}^{-1}$ ) and a nutrient medium. (b) The test solution comprised of atrazine $\left(1200 \pm 200 \mu \mathrm{g} \mathrm{L}^{-1}\right)$ and a nutrient medium. Controls inoculated with heat-killed (autoclaved) biomass were added to assess biosorption separately. 


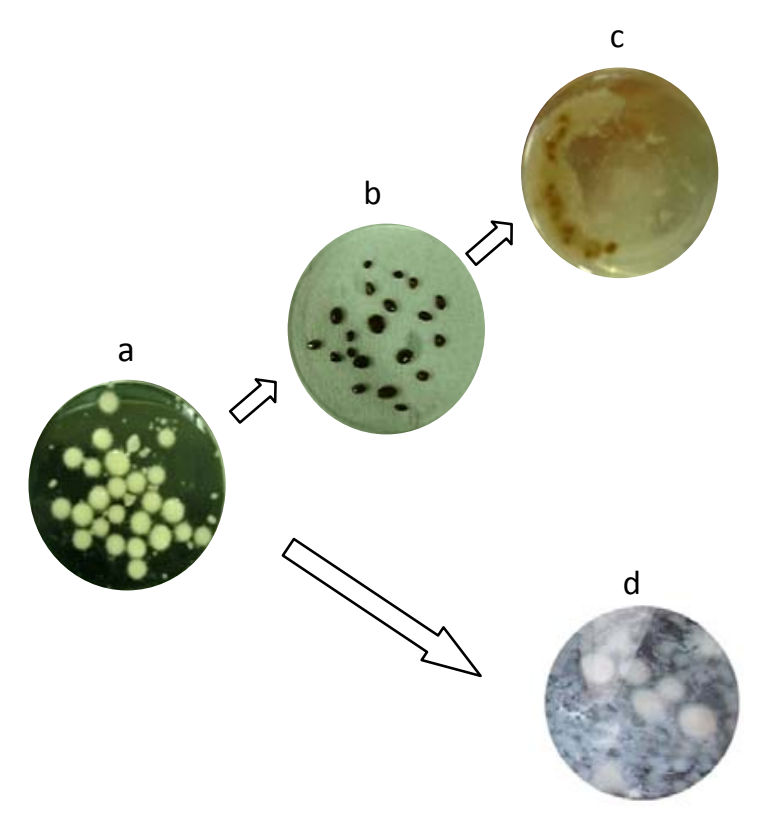

Figure 2. Difference between change of morphology of the fungus-only and the fungibacteria culture over the incubation period. (a) Firm pure fungus granules at the start of the experiment (b) Fungus granules appearing black due to being covered with activated sludge (day 3 of incubation of mixed culture batches). (c) Disintegrated fungus granules (smaller in size and deformed) still covered with activated sludge at the end of the mixed culture incubation. Presence of significant amount of fibrous structures along with granules noticeable. (d) Fungus granules (relatively more intact as compared to 'c') along with some fungus in fibrous morphology at the end of the fungus-only incubation.
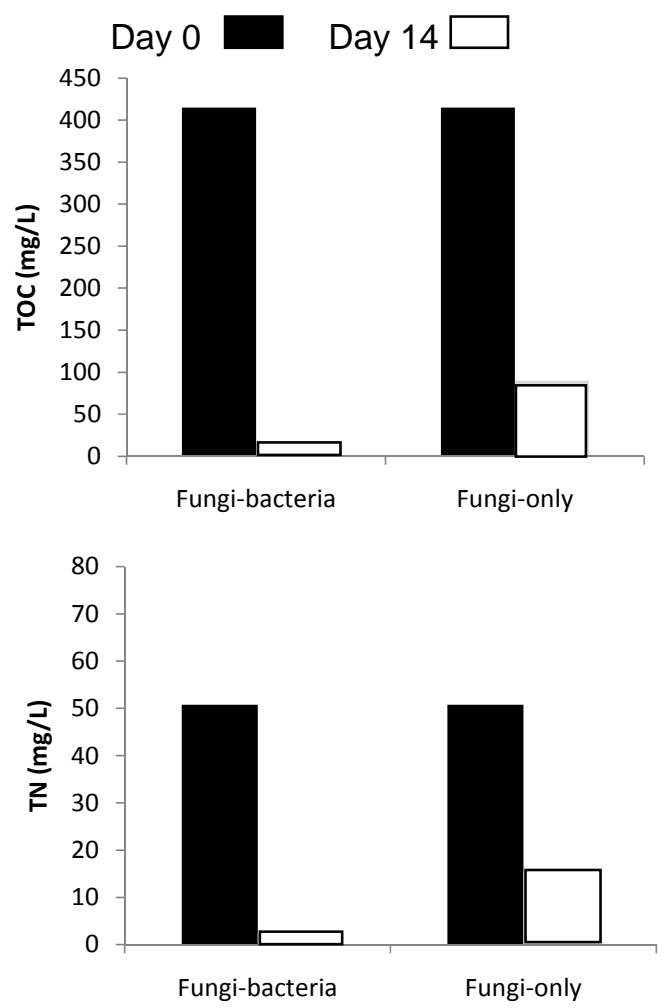

Figure 3. Concentration of TOC and TN in the batch solutions at the start and the end of the experiment showing the effect of presence of bacteria on consumption of TOC and TN. The batch test solution comprised of three pesticides and a nutrient medium. 